\title{
Research and Enlightenment of General Education Curriculum in Columbia University
}

\author{
Lin Deng
}

PhD students, College of Language and Literature, Fujian Normal University, Fuzhou, Fujian, 350007

Abstract: At present, the competition for talents in higher education around the world is very fierce. Under the demand of reform and the development trend of global higher education, the development of general education in Chinese universities is very important. As a non-professional, non-utilitarian education, general education The fundamental purpose of education is to cultivate the social responsibility of talents so that they can actively participate in social life and achieve comprehensive development. General education courses are a concentrated expression of the concept of general education. Research on the practice of general education is conducive to the improvement of the quality of talents in Chinese universities.

Keywords: Columbia University; General Education Curriculum; Inspiration

Because the general education curriculum of Columbia University has gone through three stages, it has gone from a rudimentary to a mature. Both the curriculum, itself and the content contained in the curriculum are more diversified and richer. Therefore, this article explores the general education curriculum of Columbia University. And get relevant enlightenment from it.

\section{General education}

The term general education was first proposed by Professor Packard of Broad College in the United States in 1829. This term was mainly used to clarify the importance of allowing students to learn public subjects. He believed that giving students what he believed to give students comprehensiveness. Education is conducive to the future development of students. I asked students to prepare for any major. Moreover, through such comprehensive education, students can have a comprehensive understanding of the overall situation even if they do not have specialized knowledge. Understanding. Later, Taiwanese scholars in my country made a clear definition of general education. He believed that the fundamental purpose of general education is to establish human subjectivity, realize human self-liberation, establish the interactive relationship between human and natural environment, and realize human self-awakening. .

\section{Curriculum}

How many important parts are included in the general curriculum setting system of Columbia University? They are the concepts, principles, objectives and fields of the curriculum. The elements of the curriculum concept are influenced by many aspects, such as the needs of the society, the concept of running a school, and those who need to participate. Therefore, the general curriculum concept of Columbia University has gone through three stages, from the integration of religion and secularism to practicality., And then to the development of multiple habitats. The curriculum has always adhered to the principles of basic, comprehensive, contemporary and profound. The curriculum aims to cultivate students' ability to solve problems and lead students to have a broad knowledge, which involves contemporary civilization, art, humanities, natural sports, In many fields such as foreign language and writing science, the core

This is an open-access article distributed under the terms of the Creative Commons Attribution Non-Commercial License (http://creativecommons.org/licenses/by-nc/4.0/), which permits unrestricted non-commercial use, distribution, and reproduction in any medium, provided the original work is properly cited. 
curriculum has been adhered to, and the teaching is carried out with rich content and orderly arrangements.

\section{The enlightenment of the general education curriculum of Columbia University to my country}

\subsection{Clarify the connotation of general education}

Regarding the establishment of the general education curriculum at Columbia University, there is a clear understanding of the general education itself from the beginning to the end, so it has always been able to maintain a stable direction, and promote this teaching concept throughout the school to make more and more teachers and students understand To the importance of general education courses, a balance is established between majors and general education. This is the connotation of general education courses. A wide range of knowledge content can promote the improvement of students' comprehensive quality, stimulate students' innovative and practical ability, and make students Being able to conduct professional and in-depth study for a subject will lay a good foundation for its further study and development in the future.

\subsection{Improve teachers' teaching ability}

As the controller of classroom teaching, if teachers want to make the content taught by themselves more easily accepted by students, so as to improve the teaching effect of general education courses, they must first improve their own comprehensive quality and continuously optimize their teaching ability. The teaching ability of teachers is not only their professional academic attainments. The priority in the academic field does not mean that the priority in the teaching field. Teachers must also have personality charm and moral qualities, which can have a positive impact on students. No matter how good a teacher is academically, if he has moral defects, he cannot become a qualified teacher of the people. The general education curriculum has higher requirements for teachers' teaching ability, because its teaching content is no longer limited to professional courses, so its teaching methods are also different from traditional professional curriculum teaching methods. The general education courses aim to improve students' comprehensive literacy and enable them to have a broader knowledge. This also requires teachers to have a rich knowledge base, so as to be able to become role models for students. Columbia University will also strictly screen teachers for general education courses to ensure that the teaching team has a high level of ability to receive lessons.

\subsection{Enrich the content of general education courses}

The fundamental goal of general education is to cultivate comprehensive talents with a wide range of knowledge, which also makes its teaching content no longer limited to faculties or majors, and will integrate teaching content from many fields such as nature, humanities, and social sciences, and truly achieve multi-disciplinary, Cross-field teaching. Columbia University's general education curriculum will be divided into various fields according to the core curriculum, and the curriculum syllabus will be formulated for each field, so as to facilitate students to clarify the semester study plan and give students the freedom to choose course categories. In this way, students can choose their learning content reasonably according to their own interests and learning ability, because the composition of their basic knowledge is more diversified, which is more conducive to students' professional learning.

\subsection{Create a strong humanistic atmosphere}

The general education curriculum of Columbia University also attaches great importance to the creation of a humanistic atmosphere. For example, it encourages students to read classics, organizes forums and lectures by wellknown professors or writers on campus, and enables students to listen to experts' speeches and discuss humanities ideas with masters. Develop the most direct exchanges with natural science inventions, so as to broaden students' horizons, extend their thinking, stimulate students' desire to explore the world, guide students to form correct values, and cultivate students' healthy personality. In my country, under the guidance of general education practice in research universities, the concept of general education is first practiced. The schools that offer general education courses also have a strong humanistic atmosphere, such as Peking University, Fudan University, Sun Yat-sen University, etc., under the precipitation of history Its humanistic foundation is relatively solid, and campus cultural activities are more diversified, which is very conducive to creating a strong humanistic atmosphere for general education courses. 


\section{Concluding remarks}

As an important link in university teaching, general education courses are courses designed based on the purpose of general education, which are of great significance to the cultivation of students. In the field of general education curriculum design, Columbia University's setting experience has extremely high reference value for our country, and can provide help and guidance for my country's general education curriculum design.

\section{References}

1. Xie Xin, Cai Fen. A model analysis of the structure of general education courses in American first-class universities__ Taking Harvard University, Columbia University, Princeton University, University of Chicago and Brown University as examples [J]. Teaching Research, 2020, 43(03) ): 67-75.

2. Liu Liyuan, Yu Wencai. General education in Columbia University and its enlightenment [J]. Journal of Jilin Province Education College (Late), 2015, 31(04): 46-47. 